\title{
Camouflage treatment guided by facial improvement in hyperdivergent skeletal class II malocclusion
}

\author{
Huijuan Wang ${ }^{1}$, Li Jiang ${ }^{2}$, Yating $\mathrm{Yi}^{3}$, Huang $\mathrm{Li}^{1}$, Tingting Lan ${ }^{4}$ \\ ${ }^{1}$ Department of Orthodontics, Nanjing Stomatological Hospital, Medical School of Nanjing University, Nanjing, China; ${ }^{2}$ Department of \\ Orthodontics, Sichuan Hospital of Stomatology, Chengdu, China; ${ }^{3}$ Department of Orthodontics, State Key Laboratory of Oral Diseases, National \\ Clinical Research Center for Oral Diseases, West China Hospital of Stomatology, Sichuan University, Chengdu, China; ${ }^{4}$ School of Medicine, Nankai \\ University, Tianjin, China \\ Contributions: (I) Conception and design: H Wang, H Li, T Lan; (II) Administrative support: H Li; (III) Provision of study materials or patients: L \\ Jiang; (IV) Collection and assembly of data: Y Yi; (V) Data analysis and interpretation: H Li, T Lan; (VI) Manuscript writing: All authors; (VII) Final \\ approval of manuscript: All authors. \\ Correspondence to: Tingting Lan. School of Medicine, Nankai University, No. 94 Weijin Road, Nankai, Tianjin 300071, China. Email: 1185864220@qq.com; \\ Huang Li. Department of Orthodontics, Nanjing Stomatological Hospital, Medical School of Nanjing University, No. 30 Zhong Yang's Road, Xuan \\ Wu, Nanjing 210008, China. Email: lihuang76@nju.edu.cn.
}

\begin{abstract}
Background: To detect parameters associated with the craniomaxillofacial system that could be altered during hyperdivergent skeletal class II malocclusion camouflage treatment for better profile improvement.

Methods: Forty-two subjects with hyperdivergent skeletal class II malocclusion who had finished their orthodontic treatments and achieved good soft tissue responses were included in this study. Cephalometric analyses of these patients were taken before (T1) and after (T2) treatment. Measurements were made at each treatment stage and analyzed within and between groups.

Results: No obvious decrease in the cant of occlusal plane (OP) (the line of point L1 and point L7) and mandibular plane (MP) was observed. However, an obvious decrease in the cant of the posterior occlusal plane (POP) and the angle of plane NA and plane NB (ANB) and a significant increase in the distance from the condylar center (Dc) to OP (DPO) were observed in the subjects $(\mathrm{P}<0.05)$.

Conclusions: Decreased POP canting and increased DPO values play a vital role in profile improvement. Sagittal discrepancies might be considerably alleviated by a decreasing ANB angle [especially the sella nasion A point (SNA) angle]. Therefore, to attain a successful camouflage treatment of hyperdivergent skeletal class II malocclusion, treatment should be targeted towards finding an alternative to control POP canting, including reducing crowding in the posterior arch, as well as modifying and intruding molars to an upright and lower position.
\end{abstract}

Keywords: Posterior occlusal plane (POP); facial improvement; hyperdivergent; class II malocclusion

Submitted Nov 23, 2021. Accepted for publication Feb 16, 2022.

doi: $10.21037 /$ atm-22-135

View this article at: https://dx.doi.org/10.21037/atm-22-135

\section{Introduction}

In the process of a normal growth and development, the mandible grows along with the $\mathrm{Y}$ axis with a gradual decrease occlusal plane (OP) angle to adapt the mandibular counterclockwise rotation, showing a change from a relative convex profile in childhood to a straight profile in adult; however, when hyperdivergent skeletal class II malocclusion occurred, the $\mathrm{Y}$ axis angle increased greatly to induce a clockwise rotation of the mandible and as a result, the OP angle cannot decrease to the normal level, showing a convex profile with a retracted mandible. Nowadays, the prevalence of class II malocclusion in Chinese people has reached $20.05 \%$, which is relatively high compared to other types 
of malocclusion (1), and a large proportion of these patients are accompanied by vertical discrepancy. Effective treatment outcomes could be achieved if hyperdivergent malocclusion is well controlled in childhood (2). However, many patients of the past and present generation unfortunately missed the best time for treatment. When the patients grow up, treatment is more difficult if they reject the option of surgery. Camouflage treatment can usually lead to an ideal occlusion, but it is very difficult to make distinct improvement of the subject's profile (3).

In skeletal class I patients, the relative sagittal position of maxilla and mandible is coordinated with a normal nasal profile and chin projection, showing a more attractive straight profile. However, in skeletal class II patients, the mandible is relatively retracted with a convex profile and worse, chin dysplasia and gingival smile were always accompanied in the high angle patients. Therefore, reducing the lower facial height, alleviating the mentalis tension, increasing the mentolabial sulcus depth and moving the chin forward by rotating the mandible counterclockwise are the aesthetic factors in the correction of hyperdivergent skeletal malocclusion. Moreover, making the skeletal class II relationship change to skeletal class I relationship was also important to correct the sagittal discrepancy $(4,5)$. Although the ratio of responses between the hard and soft tissue remains controversial, the behavior of the labial and chin soft tissues can be largely affected by multiple aspects, such as the lip length, lip thickness, functional status of masticatory muscles, as well as the contour and shape of the maxilla-mandible (6-11). Thus, it seems that the most important criterion for the improvement of facial appearance is to reconstruct the hard tissue and to reduce the tension in the soft tissue. Hyperdivergent skeletal class II malocclusion has always been accompanied by clockwise rotation of the mandible; therefore, several research approaches have discussed methods to allow for counter-clockwise mandible rotation $(12,13)$. Previous studies observed a continuous horizontalization of the OP accompanied by a reduction of canting in the mandibular plane (MP) during growth and development (14-17). Therefore, the key to induce the counter-clockwise rotation of the mandible is to control the OP's canting (18).

Although it is difficult to deny the important role played by the OP in malocclusion, but still we have some doubts or queries about the real behavior of the mandible followed by a change in the OP's canting in temporomandibular joint disturbance syndrome (TMD)-free adult patients. Moreover, the reconstruction ability of the supramental point $B$ in the alleviation of sagittal discrepancy in adults is questionable and constantly debated (19). In process of diagnosis, predicting the soft tissue reaction to the hard tissue is very difficult to ascertain and is a serious concern. Therefore, we designed this study in an attempt to identify measurements that changed in the hard tissues, which could improve the patient's profile (5). Different from previous studies, in this study, occlusion plane was divided into anterior and posterior occlusion plane for better distinguishing the function of anterior teeth and posterior teeth. Besides, except from an ideal occlusion relationship, an obvious improvement in facial esthetic was also an important inclusion criterion in the study population. As a result, we got an important conclusion with a key role in leveling posterior occlusal plane (POP) and thus, a sufficient space should be provided in the posterior area. We present the following article in accordance with the MDAR reporting checklist (available at https://atm.amegroups. com/article/view/10.21037/atm-22-135/rc).

\section{Methods}

The subjects were recruited from the Orthodontic Department of the Nanjing Stomatological Hospital from 2015 to 2018. The inclusion criteria of the selected subjects were as follows: (I) patients aged over 18 years old before treatment; (II) patients with hyperdivergent skeletal class II malocclusion (ANB $>5$ degrees, $\mathrm{MP}-\mathrm{FH}>32$ degrees) and four premolars extracted (bilateral maxillary and mandibular premolar) for different reasons; (III) cases where $0.022 \times 0.028$-inch labial brackets were used and space closure was processed on $0.018 \times 0.025$-inch SS archwires using a sliding mechanism. A microscrew was implanted for vertical and sagittal anchorage control when necessary. Lateral cephalometric radiographs were taken before and after treatment using a standard radiographic technique; (IV) cases where class I occlusion in molars, and normal overjet and overbite in front teeth were achieved; (V) patients with no temporomandibular joint disease or obvious facial deformity before and after treatment; and (VI) patients whose profile had significantly improved, as estimated by the change in the depth of chin-lip sulcus, the nasolabial angle, the distance from the lip to the E line, and the upper central incisor point to the GALL line (a vertical line of the horizontal plane crossing the most protruding point of the forehead). Finally, 42 samples were selected according to the above criteria.

All lateral cephalometric films were taken in the 


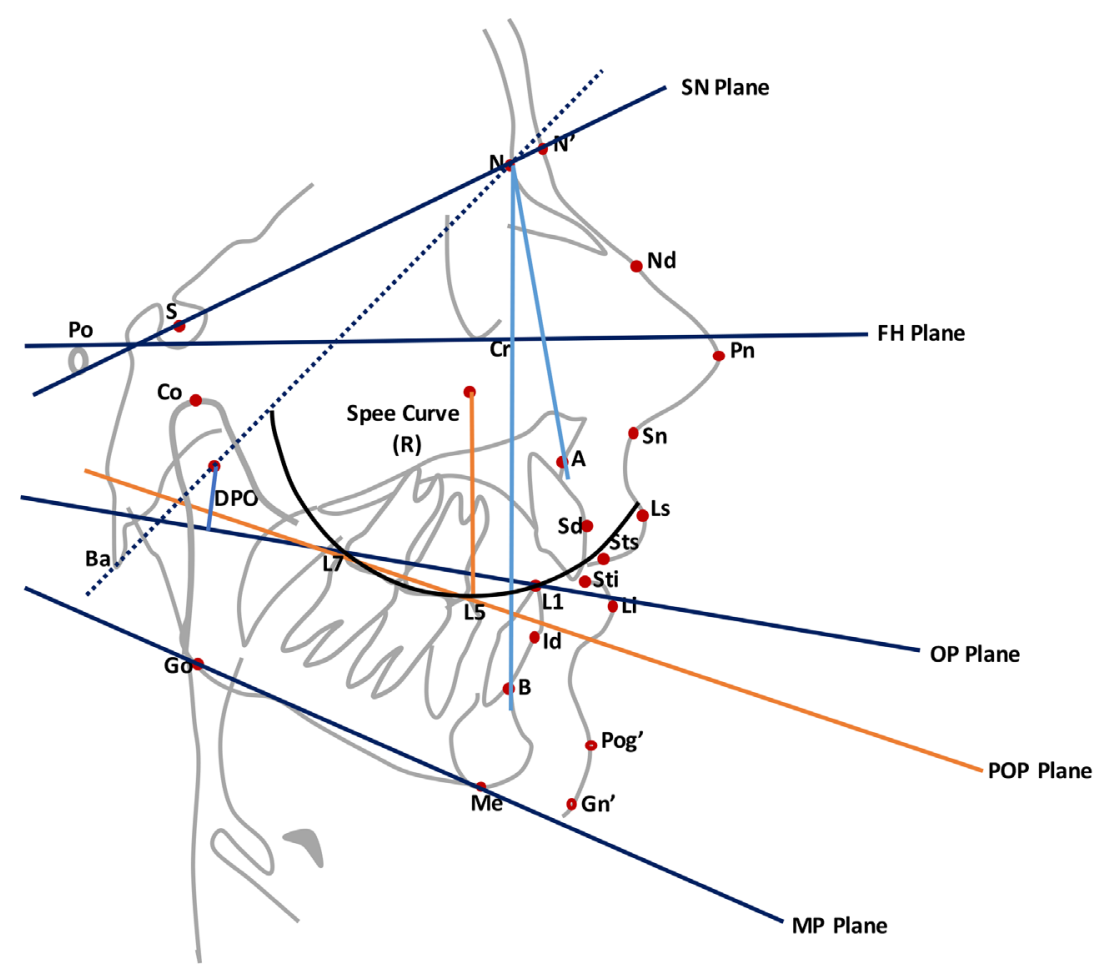

Figure 1 Landmarks, reference planes, and cephalometric measurements applied in lateral cephalometry. SN, anterior cranial base plane; FH, Frankfort plane; OP, occlusal plane; MP, mandibular plane; POP, posterior occlusal plane.

intercuspal position (ICP) and the patients' head position was fixed by the external auditory canal. The radiographs were taken by the same batch machine (Morita, Japan) under identical exposure parameters. All films were introduced into the cephalometric analysis software (GAMMA Dental software for Windows, version 7.7.14, Austria) and were simultaneously traced by the same operator. For consistency of the measurements, the lateral cephalometric images were repositioned and traced by the same surveyor after 2 weeks, and then checked by another operator. The explanation about terms and abbreviation of the lateral cephalometric parameters in this study can be seen in Figures 1,2.

The study was conducted in accordance with the Declaration of Helsinki (as revised in 2013). The study was approved by the ethics committee of Nanjing Stomatological Hospital, Medical School of Nanjing University (No. KY-2020NL-066), and informed consent was obtained from the study participants.

\section{Statistical analysis}

The data were analyzed by SPSS 19.0 for Windows (IBM
Company, Chicago, IL, USA) and the corresponding descriptive statistics (means and standard deviation) were calculated. The $t$-test was applied to compare the data before and after treatment.

\section{Results}

(I) Compared to the initial stage, the distance from the $\mathrm{Li}$ (Labrale inferius) and Ls (Labrale superius) to the E-plane largely decreased after treatment. Furthermore, the distance from the upper incisor to the GALL-line decreased from 5.47 to $0.70 \mathrm{~mm}$. These changes significantly improved the facial appearance, which seemed satisfactory for both patients and doctors (Table 1).

(II) The values of SNA (angle between NA plane and SN plane), SNB (angle between NB plane and SN plane), ANB, MP-FH (angle between MP plane and FH plane), OP-SN (angle between OP plane and SN plane), POP-SN (angle between POP plane and SN plane), U1-SN (angle between the long axis of upper central incisor and SN plane), L1-MP (angle between 


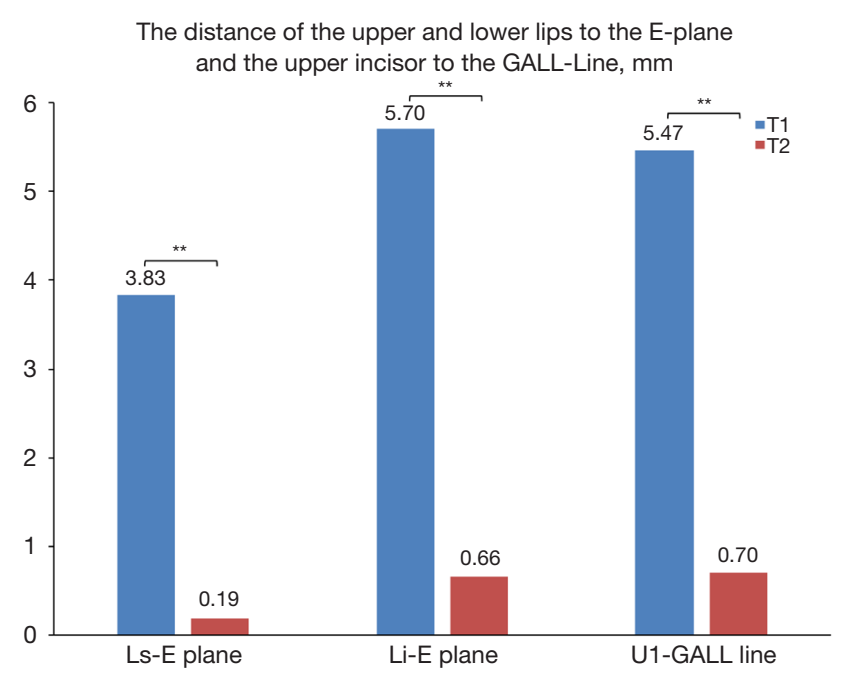

Figure 2 The distances from the upper and lower lips to the E-plane (Ls-E plane and Li-E plane) and the upper incisor to the GALL-line (U1-GALL line) before and after treatment. **, $\mathrm{P}<0.01$.

the long axis of lower central incisor and MP plane) and DPO (distance from Dc to OP) decreased after treatment. However, no significant difference was observed, except for the ANB, POP-SN, U1-SN, L1$\mathrm{MP}$, and DPO values (Tables 1,2).

(III) The ANB angle decreased from 5.66 to 4.81 degrees after treatment, which was mainly due to the decrease of the SNA angle.

(IV) Statistical analysis showed that the OP angle decreased by 2.1 degrees after treatment, but there was no significant difference compared with that before treatment. Also, it was found that the POP canting after treatment decreased by 6.52 degrees $(\mathrm{P}<0.05)$.

(V) The U1-SN angle decreased from 111.03 to 102.19 degrees, and the L1-MP angle decreased from 97.41 to 89.18 degrees. This was significant different compared with the initial stage $(\mathrm{P}<0.001)$.

(VI) The DPO value increased from 19.3 to $23.2 \mathrm{~mm}$ after treatment, which was consistent with the significantly decreased OP and increase facial height ratio, indicating a counterclockwise rotation of the mandible and a reduction in the mandible angle.

\section{Discussion}

In clinical practice, a large number of patients with hyperdivergent skeletal class II malocclusion wish to
Table 1 Landmarks, reference planes, and cephalometric measurements applied in cephalometry

\begin{tabular}{ll}
\hline Abbreviation & Definition \\
\hline Skeletal landmarks \\
S & Sella \\
N & Nasion \\
Po & Porion \\
Or & Orbitale \\
A & Subspinale \\
B & Supramental \\
Go & Gonion \\
Co & Condylion \\
Ba & Basion \\
Dc & The midpoint of the joint between the line drawn \\
& by point Baand point N
\end{tabular}

Soft tissue landmarks

$\begin{array}{ll}\text { Pn } & \text { The tip of nose } \\ \text { Sn } & \text { Soft tissue nasion } \\ \text { Ls } & \text { Labrale superius } \\ \mathrm{Li} & \text { Labrale inferius } \\ \text { Pog' } & \text { Soft tissue pogonion }\end{array}$

Dental landmarks

L1 The mandibular incisor edge

L7 The second mandibular molar distal cusp

Reference planes

$\mathrm{SN} \quad$ The line of point $\mathrm{S}$ and point $\mathrm{N}$

$\mathrm{FH} \quad$ The line of point $\mathrm{Po}$ and point $\mathrm{Or}$

OP The line of point L1 and point L7

MP The line of point Go and point Me

POP The line drawn from the cusp tip of the lower second premolar to the distal cusp of the lower second molar at the

SN, anterior cranial base plane; FH, Frankfort plane; OP, occlusal plane; MP, mandibular plane; POP, posterior occlusal plane.

improve their facial appearance through camouflage orthodontic treatment (3). However, this type of malocclusion has always been characterized by a retruded and backward rotated mandible, a relative protrusive maxilla, and a convex profile. This malocclusion is a huge 
Table 2 The means, standard deviations, and t-test of the angular and line measurements before and after treatment

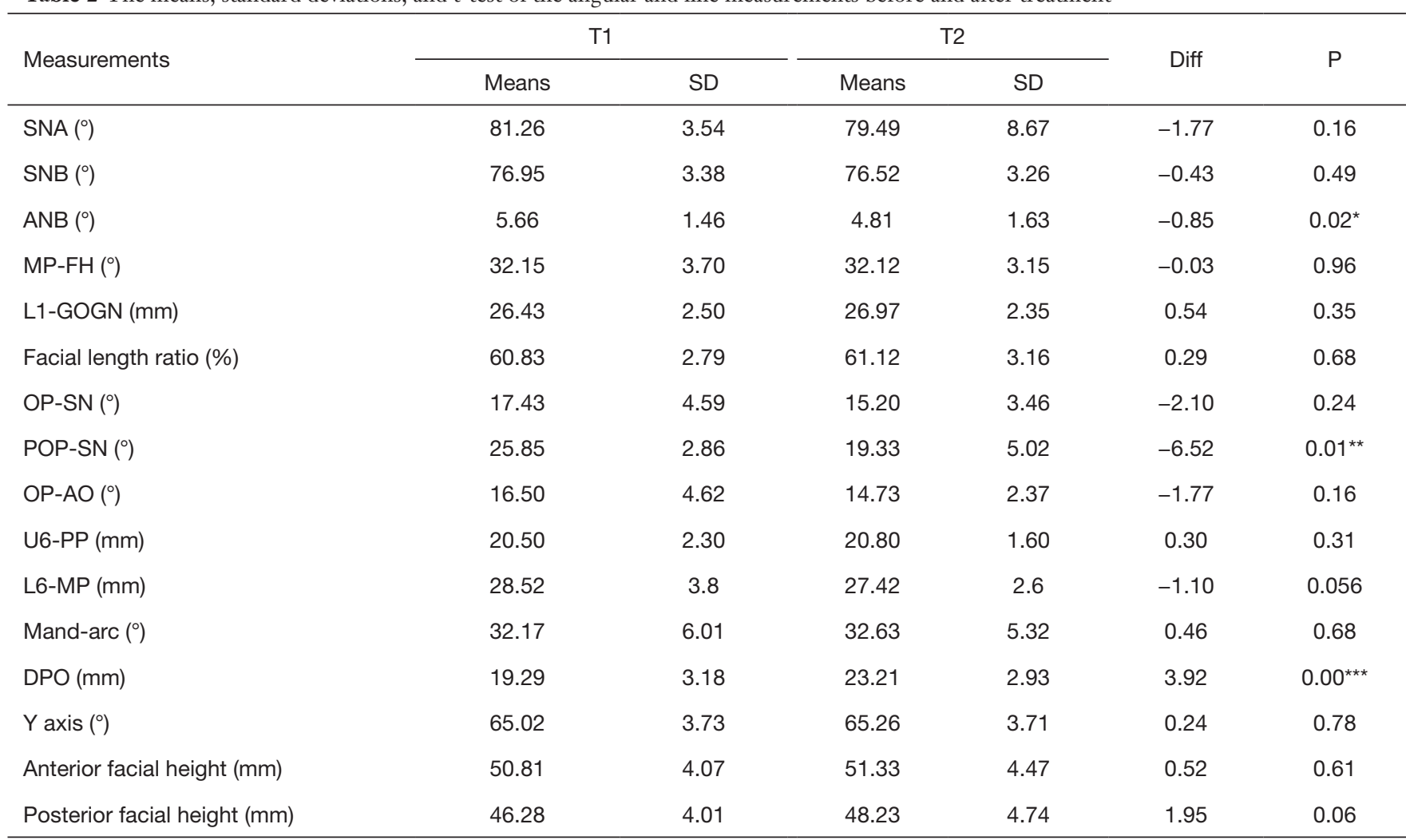

${ }^{*}, \mathrm{P}<0.05 ;{ }^{* *}, \mathrm{P}=0.01 ;{ }^{* \star *}, \mathrm{P}<0.001$. SNA $\left({ }^{\circ}\right)$, angle of sella nasion $\mathrm{A}$ point; SNB $\left({ }^{\circ}\right)$, angle of sella nasion $\mathrm{B}$ point; ANB $\left({ }^{\circ}\right)$, angle of plane NA and plane NB; MP-FH $\left({ }^{\circ}\right)$, mandibular plane angle; L1-GOGN $(\mathrm{mm})$, lower incisor length; OP-SN $\left(^{\circ}\right)$, occlusal plane angle; POP-SN $\left({ }^{\circ}\right)$, posterior occlusal plane angle; U6-PP $(\mathrm{mm})$, upper molar length; L6-MP $(\mathrm{mm})$, lower molar length; Mand-arc $\left(^{\circ}\right)$, mandibular shape.

challenge in orthodontics because of the demand for the correction of both sagittal and vertical discrepancies $(17,18,20)$. In this study, we selected 42 patients whose profile improved significantly and became close to normal, with a marked decrease in the distance from the upper and lower lips to the E-plane and the distance from the upper incisor to the GALL-line. A large decrease in the $\mathrm{U} 1-\mathrm{SN}$ and L1-MP angles may play a vital role in profile improvement.

It has been reported that the reduction of OP canting accompanied by the counter-clockwise mandibular rotation will occur during camouflage treatment (18), which is effective for vertical control. Our results showed that $\mathrm{OP}$ canting decreased from 17.43 degrees in $\mathrm{T} 1$ to 15.2 degrees in $\mathrm{T} 2$. This consequence is consistent with previous research; yet, there was no statistical difference between $\mathrm{T} 1$ and $\mathrm{T} 2$, which suggested that the improved response of the soft tissue to the hard tissue may not be mainly attributed to the OP change. While analyzing the angle of MP, we found that there was almost no change after treatment (35.15 vs. 35.12 degrees, $\mathrm{P}=0.96$ ), although the patients' profiles improved as observed. The strong correlation of decreased OP canting accompanied by the counter-clockwise rotation of the mandible was not found in our study, which was contrary to previous reports. We speculate that the counter-clockwise rotation of the mandible in adults may be difficult to occur, as per previous investigations $(18,20,21)$.

However, we were very surprised to find that POP canting decreased significantly from 25.9 to 19.8 degrees, showing some similarity to the conclusions drawn by Fushima et al., which suggested that POP was more important than OP for vertical control (20). OP is defined as a line from the tip of the lower incisor to the distal cusp of the lower second molar, but it is a well-known fact that excessive Spee curve can often be seen in class II division 1 malocclusions (22). A deep Spee curve could affect the skeletal growth pattern and masticatory function, highlighting the critical importance 
of the Spee curve. During the course of observing the OP from the sagittal direction, we could see that the lowest point was on the second premolar and the first molar; the line defined by OP will neglect the canting of the posterior teeth. Therefore, more attention should be paid to the POP in camouflage orthodontic treatment of hyperdivergent class II malocclusion $(20,22,23)$. We speculate that decreasing POP canting can change the force system in the temporomandibular joint (TMJ), which can improve the function of the masticatory system, reduce the tension of the soft tissue, and make the whole maxillofacial soft tissue look more harmonious. Therefore, in profile improvement, controlling POP is more important than controlling OP (24). In clinical practice, the congestion of the posterior teeth must be resolved in time so that POP canting can be decreased by uprighting and intruding the molars.

DPO could reflect some information about the canting of OP and the growth trend of the mandible. Generally, the smaller of the DPO value, the more class II it tends to be; and the larger of the DPO value, the more class III it tends to be. In our study, we found that the DPO value increased significantly in $\mathrm{T} 2$, which reflected the relief of the class II malocclusion.

The correction of the class II malocclusion could be achieved by the forward movement of the mandible to minimize the ANB angle (24). In our analysis, the reason for the ANB angle decrease was mainly due to the decrease of SNA ( $\Delta$ denoted the changes resulting from T2 minus $\left.\mathrm{T} 1, \Delta \mathrm{SNA}=-1.77^{\circ}, \mathrm{P}=0.16\right)$ rather than an increase $\left(\triangle \mathrm{SNB}=-0.43^{\circ}, \mathrm{P}=0.49\right)$. This is reasonable because moving the mandible forward is very difficult in adults. In many premolar extraction cases, retraction of point $\mathrm{A}$ by controlling the root movement of the maxillary anterior teeth is effective for the alleviation of sagittal discrepancy, and the sagittal position of the upper lip is in accordance to the change of point $\mathrm{A}(25)$.

\section{Conclusions}

(I) The key to significant profile improvement in camouflage orthodontic treatment of hyperdivergent skeletal class II malocclusion was to control POP canting;

(II) Decrease of the SNA angle played a critical role in the correction of the sagittal discrepancy, as opposed to an increased in the SNB angle;

(III) Profile improvement of hyperdivergent class II malocclusion may be attributed to the alleviation of soft tissue tension and the retraction of point A, instead of the counter-clockwise and moving forward of the mandible.

\section{Acknowledgments}

We sincerely appreciate all lab members. Funding: None.

\section{Footnote}

Reporting Checklist: The authors have completed the MDAR reporting checklist. Available at https://atm.amegroups. com/article/view/10.21037/atm-22-135/rc

Data Sharing Statement: Available at https://atm.amegroups. com/article/view/10.21037/atm-22-135/dss

Conflicts of Interest: All authors have completed the ICMJE uniform disclosure form (available at https://atm. amegroups.com/article/view/10.21037/atm-22-135/coif). The authors have no conflicts of interest to declare.

Ethical Statement: The authors are accountable for all aspects of the work in ensuring that questions related to the accuracy or integrity of any part of the work are appropriately investigated and resolved. The study was conducted in accordance with the Declaration of Helsinki (as revised in 2013). The study was approved by the ethics committee of Nanjing Stomatological Hospital, Medical School of Nanjing University (No. KY-2020NL-066), and informed consent was obtained from the study participants.

Open Access Statement: This is an Open Access article distributed in accordance with the Creative Commons Attribution-NonCommercial-NoDerivs 4.0 International License (CC BY-NC-ND 4.0), which permits the noncommercial replication and distribution of the article with the strict proviso that no changes or edits are made and the original work is properly cited (including links to both the formal publication through the relevant DOI and the license). See: https://creativecommons.org/licenses/by-nc-nd/4.0/.

\section{References}

1. Fu M, Zhang D, Wang B, et al. The prevalence of malocclusion in China--an investigation of 25,392 children. 
Zhonghua Kou Qiang Yi Xue Za Zhi 2002;37:371-3.

2. Bendeus $M$, Hägg $U$, Rabie B. Growth and treatment changes in patients treated with a headgear-activator appliance. Am J Orthod Dentofacial Orthop 2002;121:376-84.

3. Kiyak HA, Vitaliano PP, Crinean J. Patients' expectations as predictors of orthognathic surgery outcomes. Health Psychol 1988;7:251-68.

4. Dolce C, Hatch JP, Van Sickels JE, et al. Five-year outcome and predictability of soft tissue profiles when wire or rigid fixation is used in mandibular advancement surgery. Am J Orthod Dentofacial Orthop 2003;124:24956; quiz 340.

5. Shaughnessy S, Mobarak KA, Høgevold HE, et al. Long-term skeletal and soft-tissue responses after advancement genioplasty. Am J Orthod Dentofacial Orthop 2006;130:8-17.

6. Betts NJ. Changes in nasal and labial soft tissues after surgical repositioning of the maxilla. J Oral Maxil Surg 1989;47:142.

7. Ewing M, Ross RB. Soft tissue response to mandibular advancement and genioplasty. Am J Orthod Dentofacial Orthop 1992;101:550-5.

8. Filho HN, Gonçales ES, Berrentin-Felix G, et al. Evaluation of the facial soft tissues following surgically assisted maxillary expansion associated with the simple V-Y suture. Int J Adult Orthodon Orthognath Surg 2002;17:89-97.

9. Gallagher DM, Bell WH, Storum KA. Soft tissue changes associated with advancement genioplasty performed concomitantly with superior repositioning of the maxilla. J Oral Maxillofac Surg 1984;42:238-42.

10. Lines PA, Steinhauser EW. Soft tissue changes in relationship to movement of hard structures in orthognathic surgery: a preliminary report. J Oral Surg 1974;32:891-6.

11. Mobarak KA, Espeland L, Krogstad O, et al. Soft tissue profile changes following mandibular advancement surgery: predictability and long-term outcome. Am J Orthod Dentofacial Orthop 2001;119:353-67.

12. Majourau A, Nanda R. Biomechanical basis of vertical dimension control during rapid palatal expansion therapy. Am J Orthod Dentofacial Orthop 1994;106:322-8.

13. Pearson LE. Vertical control in treatment of patients having backward-rotational growth tendencies. Angle Orthod 1978;48:132-40.

14. Bergersen EO. The directions of facial growth from infancy to adulthood. Angle Orthod 1966;36:18-43.
15. Bhatia SN. A longitudinal study of the SN-mandibular-, Frankfurt-mandibular-, and maxillary-mandibular-plane angles. Trans Br Soc Study Orthod 1969-1970;5:169-73.

16. Bhatia SN, Leighton BC. Manual of facial growth: a computer analysis of longitudinal cephalometric growth data. Oxford University Press, Inc.; 1993.

17. Tanaka EM, Sato S. Longitudinal alteration of the occlusal plane and development of different dentoskeletal frames during growth. Am J Orthod Dentofacial Orthop 2008;134:602.e1-11; discussion 602-3.

18. Ye R, Li Y, Li X, et al. Occlusal plane canting reduction accompanies mandibular counterclockwise rotation in camouflaging treatment of hyperdivergent skeletal Class II malocclusion. Angle Orthod 2013;83:758-65.

19. Sankey WL, Buschang PH, English J, et al. Early treatment of vertical skeletal dysplasia: the hyperdivergent phenotype. Am J Orthod Dentofacial Orthop 2000;118:317-27.

20. Fushima K, Kitamura Y, Mita H, et al. Significance of the cant of the posterior occlusal plane in class II division 1 malocclusions. Eur J Orthod 1996;18:27-40.

21. Gkantidis N, Halazonetis DJ, Alexandropoulos E, et al. Treatment strategies for patients with hyperdivergent Class II Division 1 malocclusion: is vertical dimension affected? Am J Orthod Dentofacial Orthop 2011;140:346-55.

22. Salzmann JA. Technique and treatment with light-wire edgewise appliances. American Institute of Electrical Engineers Proceedings 1972;28:605-31.

23. Hanashima M, Sakakibara K, Slavicek R, et al. A study regarding occlusal plane and posterior disocclusion. International Journal of Stomatology \& Occlusion Medicine 2008;1:27-33.

24. Celikoglu M, Unal T, Bayram M, et al. Treatment of a skeletal Class II malocclusion using fixed functional appliance with miniplate anchorage. Eur J Dent 2014;8:276-80.

25. Malta LA, Baccetti T, Franchi L, et al. Long-term dentoskeletal effects and facial profile changes induced by bionator therapy. Angle Orthod 2010;80:10-7.

(English Language Editor: A. Kassem)

Cite this article as: Wang $\mathrm{H}$, Jiang $\mathrm{L}, \mathrm{Yi} \mathrm{Y,} \mathrm{Li} \mathrm{H,} \mathrm{Lan} \mathrm{T.}$ Camouflage treatment guided by facial improvement in hyperdivergent skeletal class II malocclusion. Ann Transl Med 2022;10(4):163. doi: 10.21037/atm-22-135 